\title{
Patterns and predictors of exercise behavior during 24 months of follow-up after a supervised exercise program during breast cancer chemotherapy
}

Ki-Yong An ${ }^{1}$, Dong-Woo Kang ${ }^{1}$, Andria R. Morielli', Christine M. Friedenreich ${ }^{2,3}$, Robert D. Reid ${ }^{4}$, Donald C. McKenzie ${ }^{5}$, Karen Gelmon ${ }^{5,6}$, John R. Mackey ${ }^{1,7}$ and Kerry S. Courneya ${ }^{1 *}$

\begin{abstract}
Background: Understanding the longer-term exercise behavior of patients with breast cancer after chemotherapy is important to promote sustained exercise. The purpose of the current study was to report the longer-term patterns and predictors of exercise behavior in patients with breast cancer who exercised during chemotherapy.

Methods: In the Combined Aerobic and Resistance Exercise (CARE) Trial, 301 patients with breast cancer were randomized to three different exercise prescriptions during chemotherapy. Exercise behaviors after chemotherapy were self-reported at 6-, 12-, and 24-month follow-up. Exercise patterns were identified by categorizing patients according to which exercise guideline they were meeting (neither, aerobic only, resistance only, or combined) at each of the three follow-up timepoints (64 possible patterns). Predictors of longer-term exercise behavior included physical fitness, patient-reported outcomes, and motivational variables from the theory of planned behavior assessed at postintervention (postchemotherapy). Univariate and multivariate stepwise multinomial logistic regression and linear regression were used for statistical analyses.

Results: A total of 264 (88\%) participants completed all three follow-up exercise behavior assessments and exhibited 50 different exercise patterns. Postintervention aerobic fitness was the most consistent predictor of longer-term exercise behavior at all three timepoints. For example, higher aerobic fitness (per $1 \mathrm{ml} / \mathrm{kg} / \mathrm{min}$ ) predicted better adherence to the "aerobic only" (OR $=1.09 ; p=0.005)$ and "combined" (OR $=1.12 ; p<0.001)$ guidelines compared to "neither" guideline at 6-month follow-up. Additionally, higher postintervention muscular strength (per $1 \mathrm{~kg}$ ) was associated with better adherence to the "resistance only" (OR=1.07; $p=0.025)$ and "combined" (OR $=1.08 ; p<0.001)$ guidelines compared to "neither" guideline at 24-month follow-up. Finally, lower perceived difficulty (per 1 scale point) was associated with better adherence to the "combined" ( $\mathrm{OR}=0.62 ; p=0.010)$ and "aerobic only" $(\mathrm{OR}=0.58 ; p=0.002)$ guideline compared to the "neither" guideline at the 24-month follow-up.
\end{abstract}

Conclusions: Our study is the first to show that the longer-term exercise patterns of patients with breast cancer who exercised during chemotherapy are diverse and predicted by physical fitness and motivational variables after chemotherapy. Our novel implications are that improving physical fitness during chemotherapy and applying motivational counseling after chemotherapy may improve longer-term exercise behavior in patients with breast cancer.

Trial registration: (NCT00249015).

Keywords: Breast cancer, Cancer survivors, Exercise behavior, Exercise pattern, Physical activity, Determinants, Healthrelated fitness

\footnotetext{
*Correspondence: kerry.courneya@ualberta.ca

${ }^{1}$ Faculty of Kinesiology, Sport, and Recreation, University of Alberta,

Edmonton, Alberta T6G 2H9, Canada

Full list of author information is available at the end of the article
}

(c) The Author(s). 2020 Open Access This article is distributed under the terms of the Creative Commons Attribution 4.0 International License (http://creativecommons.org/licenses/by/4.0/), which permits unrestricted use, distribution, and reproduction in any medium, provided you give appropriate credit to the original author(s) and the source, provide a link to the Creative Commons license, and indicate if changes were made. The Creative Commons Public Domain Dedication waiver (http://creativecommons.org/publicdomain/zero/1.0/) applies to the data made available in this article, unless otherwise stated. 


\section{Introduction}

Exercise is physical activity that is planned, structured, repetitive, and purposive with the goal of improving or maintaining one or more components of physical fitness [1]. Exercise during breast cancer chemotherapy improves physical functioning [2], health-related fitness [2-5], treatment-related symptoms [2, 4, 5], self-esteem [3], sleep quality [6], chemotherapy completion rate $[3,5]$, and possibly even disease-specific and overall survival [7]. Unfortunately, many of the benefits of exercise during breast cancer chemotherapy dissipate quickly after cessation of the exercise program. Some studies have shown diminished effects as early as 6 months postintervention [5, 8-10] and few trials have even reported longer-term effects beyond 6 months [11-14]. We recently reported the 6-, 12-, and 24month follow-up of the Combined Aerobic and Resistance Exercise (CARE) Trial which compared different types and doses of exercise during breast cancer chemotherapy [15]. We found that few of the short-term positive effects of the higher-dose aerobic and combined exercise programs during chemotherapy [2] were maintained during follow-up [15]. Conversely, there were strong positive associations between exercise behavior during the follow-up period and longer-term physical fitness, psychosocial outcomes, and quality of life [15]. These data suggest that longer-term maintenance of exercise after chemotherapy is critical for the sustained benefits of exercise.

Despite the importance of maintaining exercise after breast cancer chemotherapy, few studies have reported longer-term follow-up data on exercise behavior [11, 13, 14] and its determinants [14, 16, 17]. Moreover, these studies have reported mixed findings. One study reported no difference in exercise levels between the exercise and the control groups at 1-year follow-up [14] while some studies have reported higher physical activity in the exercise groups compared to the control groups even at four- or five-year follow-up [11, 13]. Findings on the determinants of exercise behavior regarding demographic, medical, motivational, and fitness variables have also been mixed [14, 16, 17]. Given that supervised exercise is emerging as a standard of care in this clinical setting, understanding exercise behavior and its determinants after a supervised exercise intervention during breast cancer chemotherapy is important to guide clinical and public health interventions.

The purpose of the current study was to report the longer-term exercise behavior patterns and predictors in survivors of breast cancer during the 24-month follow-up period in the CARE Trial. We included demographic and medical variables, patient-reported outcomes, health-related fitness outcomes, and motivational variables from the theory of planned behavior [18] as the candidate predictors based on previous findings $[16,17,19-21]$. We hypothesized that exercise participation rates would decline during follow-up and that few survivors of breast cancer would be meeting the combined aerobic and resistance exercise guidelines. Moreover, we hypothesized that younger age, better physical fitness, higher motivation, and lower fatigue would predict longer-term exercise behavior. Specifically, we hypothesized that higher aerobic fitness would predict greater adherence to the aerobic exercise guideline, while higher muscular strength and muscular endurance would predict better adherence to the resistance exercise guideline. The identification of exercise behavior patterns across the 6-, 12-, and 24-month follow-ups was considered exploratory.

\section{Methods}

\section{Setting and participants}

The methods of the CARE Trial have been reported elsewhere [2]. Briefly, the CARE Trial was a multicenter trial in Edmonton, Alberta; Ottawa, Ontario; and Vancouver, British Columbia. Ethics was approved for all three centers and written informed consent was obtained from all participants prior to trial enrollment. Participants were eligible for the study if they were women who could speak and understand English or French, were not pregnant, were aged 18 years or older, had stage I -IIIc breast cancer, and were initiating adjuvant chemotherapy. Women were excluded if they had incomplete axillary surgery, transverse rectus abdominis muscle reconstructive surgery, significant health problems, were not approved by their oncologist or, if they were performing structured vigorous-intensity exercise.

\section{Design and procedures}

The study was a prospective, three-armed, randomized controlled trial. Patient-reported outcomes, including exercise behavior, were assessed at baseline, twice during chemotherapy, postintervention (postchemotherapy), and at 6-, 12-, and 24-month follow-up. Health-related fitness outcomes (i.e., body composition, aerobic fitness, and muscular fitness) were assessed at baseline, postintervention, and at the 12-month follow-up timepoint. After completing all baseline assessments, participants were stratified by center and chemotherapy protocol and randomly assigned in a 1:1:1 ratio to three exercise groups that performed a thriceweekly (a) standard dose of 25-30 min of aerobic exercise (STAN), (b) a higher dose of 50-60 min of aerobic exercise (HIGH), or (c) a combined dose of 50-60 min of aerobic and resistance exercise (COMB).

\section{Exercise training intervention}

The exercise training interventions have been described elsewhere [2]. Briefly, participants started the exercise intervention within 1-2 weeks of their first chemotherapy infusion and completed it within 3-4 weeks after their last chemotherapy infusion. The exercise programs were developed based on the Physical Activity Guidelines for Americans (USDHHS, [22], which have been endorsed for cancer 
survivors by the American College of Sports Medicine [4] and the American Cancer Society [23]. These guidelines recommend at least $75 \mathrm{~min} /$ week of vigorous-intensity aerobic exercise or $150 \mathrm{~min} /$ week of moderate-intensity aerobic exercise or any combination thereof. In the CARE trial, the STAN group was asked to follow the minimum physical activity recommendation and perform $75 \mathrm{~min} /$ week of vigorous-intensity aerobic exercise on either a cycle ergometer, treadmill, elliptical, rowing ergometer, or any combination of these modalities (i.e., 3 days/week for $25-30 \mathrm{~min} /$ session). The HIGH group was asked to double the minimum recommendation and perform $150 \mathrm{~min} /$ week of vigorous-intensity aerobic exercise (i.e., 3 days/week for 50 $60 \mathrm{~min} / \mathrm{session}$ ). The COMB group was asked to follow the same aerobic exercise guidelines as the STAN group plus a standard resistance exercise program 3 days/week, consisting of two sets of 10-12 repetitions of nine different resistance exercises (e.g. leg extension, leg curl, leg press, calf raise, chest press, seated row, triceps extension, biceps curl, and modified curl-up) at $60-75 \%$ of their estimated onerepetition maximum (1RM) per session. The initial intensity of the aerobic exercise was individualized but generally began at $55-60 \%$ of peak oxygen consumption $\left(\mathrm{VO}_{2 \text { peak }}\right)$ and progressed to $70-75 \%$ of $\mathrm{VO}_{2 \text { peak }}$ by week 6 . Initial exercise duration was also individualized but generally began with sessions lasting $15-30 \mathrm{~min}$ and reached $25-30 \mathrm{~min} / \mathrm{ses}-$ sion by week 4 (STAN and COMB) or $50-60 \mathrm{~min} / \mathrm{session}$ by week 6 (HIGH). All exercise sessions were supervised by qualified exercise physiologists in the exercise facilities in or near the medical centers at each study location. The exercise intervention was performed only during chemotherapy which ranged from 12 to 18 weeks (median of 17 weeks). After the postintervention assessments, participants were given an exercise prescription for both aerobic and resistance exercise, however, they were free to do whatever exercise they chose and they received no further intervention.

\section{Assessment of exercise behavior during follow-up}

Exercise behavior was assessed by a modified version of the Godin Leisure-Time Exercise Questionnaire [24] at baseline, 6-, 12-, and 24-month follow-up. The Godin LeisureTime Exercise Questionnaire contains three questions that assess the average frequency of light intensity (e.g., easy walking, bowling), moderate-intensity (e.g., fast walking, folk dancing), and vigorous-intensity (e.g., running, crosscountry skiing) exercise during free time in a typical week over the past month. We modified the questionnaire to include the average duration of exercise and to refer to a typical week over the past six months (6- and 12- month assessments) or over the past year (24- month assessment). We also included a separate question asking about the average duration and frequency of resistance exercise (e.g., use of free weights or universal equipment at home or at a fitness center). Participants were then categorized into four groups based on the American College of Sports Medicine [4] exercise guidelines for cancer survivors: (a) meeting "neither" exercise guideline; (b) meeting the "resistance only" guideline (i.e. $\geq 2$ days/week of resistance exercise); (c) meeting the "aerobic only" guideline (i.e. $\geq 75 \mathrm{~min} /$ week of vigorous-intensity aerobic exercise or $\geq 150 \mathrm{~min} /$ week of moderate-intensity aerobic exercise or an equivalent combination); and (d) meeting the "combined" guidelines.

\section{Assessment of predictors}

Exercise behavior predictors included non-modifiable factors such as demographic and medical variables, and modifiable factors such as patient-reported outcomes, health-related fitness outcomes, and Theory of Planned Behavior (TPB) variables based on previous findings showing several demographic [17, 19-21], motivational $[16,17]$, medical [16, 17], and health-related fitness [17] variables predicted exercise behavior in survivors of breast cancer. Demographic and health behavior information was collected at baseline by self-report and consisted of age ( $<50$ years versus $\geq 50$ years), marital status (not married versus married), education (did not complete University/College versus completed University/College), annual family income $(\geq \$ 80,000$ versus $<\$ 80,000)$, employment status (unemployed versus employed), smoking status (non-smoker versus smoker), menopausal status (premenopausal versus peri and post-menopausal), group assignment (STAN versus HIGH versus COMB), and location/center (Ottawa versus Edmonton versus Vancouver).

Medical variables were collected from medical records and consisted of disease stage (I/IIa versus IIb/IIIa), type of surgery (lumpectomy versus mastectomy), and chemotherapy variables including chemotherapy type (i.e. taxane versus no taxane; anthracycline versus no anthracycline) and length of chemotherapy (i.e. 4 cycles (12 weeks) versus $6+$ cycles $(18+$ weeks)).

Patient-reported outcomes were collected by self-report and consisted of the Medical Outcomes Survey Short Form (SF)-36 [25], Functional Assessment of Cancer TherapyBreast (FACT-B) [26], FACT-Fatigue (FACT-F) [27], FACT-Endocrine Symptoms (FACT-ES) [28], FACTTaxane [29], Perceived Stress Scale [30], revised Happiness Measure [31], Rosenberg Self-Esteem Scale [32], Center for Epidemiological Studies-Depression Scale (CES-D)-short form version [33-35], Spielberger State Anxiety Inventory [36], and Pittsburgh Sleep Quality Index (PSQI) [37, 38].

Health-related fitness assessments have been described elsewhere [2] and consisted of aerobic fitness $\left(\mathrm{VO}_{2}\right.$ peak) assessed by a maximal incremental exercise test on a treadmill; upper and lower body muscular strength and endurance assessed through chest and leg press tests; and body composition assessed using dual $\mathrm{x}$-ray absorptiometry (DEXA). 
TPB motivational variables were assessed by single items on a five-point scale [18] that have been commonly used in exercise and cancer survivor studies [17, 39-42]. Participants were asked to anticipate how beneficial, enjoyable, supported, motivated, and difficult they thought it would be to exercise over the next six months and if they had a detailed plan for where, when, and how they were going to exercise. Assessment of patient-reported outcomes, healthrelated fitness outcomes, and TPB variables at postintervention (postchemotherapy) were used for analyses.

\section{Statistical analyses}

To ascertain the patterns of exercise behavior during the follow-up period, we identified the exercise behaviors (i.e., combined, aerobic only, resistance only, or neither) at each time point (i.e., 6 months, 12 months, and 24 months) and classified the exercise patterns based on all the possible combinations of exercise behavior spanning the three time points $(4 \times 4 \times 4=64$ possible patterns). For ease of interpretation, we then ignored the order of the exercise behaviors across the three timepoints and collapsed these 64 patterns into 14 possible patterns which included all the possible combinations of 1 (same exercise behavior at all 3 timepoints), 2 (2 different exercise behaviors during 3 timepoints), or 3 (a different exercise behavior at each timepoint). To analyze predictors across the three timepoints, we further categorized exercise patterns based on the number of times $(0,1,2$, or 3$)$ "combined" or "neither" was reported in the exercise pattern.

To identify predictors of exercise behavior at each follow-up timepoint, we analyzed the univariate associations between the predictors and follow-up exercise behaviors using $x^{2}$ analyses for nominal variables and analyses of variance for continuous variables. Where possible, we dichotomized nominal variables based on standard groupings (e.g., age: < 50 versus $\geq 50$ years; marital status: not married versus married; education level: did not complete University/college versus completed University/college). Health-related fitness outcomes, patientreported outcomes, and motivational variables were analyzed as continuous variables with odds ratios (ORs) reported per whole unit of the measure (e.g., $1 \mathrm{ml} / \mathrm{kg} / \mathrm{min}$ for aerobic fitness, $1 \mathrm{~kg}$ for the muscular strength measure, 1 repetition for the muscular endurance measure, 1 point on the 1-5 motivation scales, etc.). Predictor variables that had statistically significant univariate associations $(p<$ 0.05 ) with exercise behaviors at each timepoint were further examined using a forward stepwise multinomial logistic regression to identify the main predictors of exercise behaviors at each timepoint. ORs (and inverse) of 1.68 (0.60), $3.47(0.29)$, and $6.71(0.15)$ are considered small, medium, and large effects, respectively [43].

We followed the same method to determine associations between predictors and exercise patterns based on the number of times "combined" or "neither" was reported in the exercise pattern (ranging from 0 to 3 ). We analyzed the univariate associations using $x^{2}$ analyses for nominal variables and analyses of variance for continuous variables. Predictor variables that had statistically significant univariate associations $(p<0.05)$ were examined in a linear regression model using the forward stepwise method to identify the main predictors of the "combined" and the "neither" exercise behaviors. Statistical analyses were performed using SPSS statistical software (IBM SPSS statistics 26).

\section{Results}

Flow of participants during the follow-up phase of the CARE Trial has been reported elsewhere [15]. Briefly, of the 301 randomized participants, 264 (88\%) provided complete data at all three follow-up timepoints. Baseline characteristics of the CARE Trial participants have also been reported elsewhere [2]. For the 264 participants analyzed in the present study, the mean (and standard deviation) for age was 50.0 (8.7) years, and for BMI was $26.3(5.5) \mathrm{kg} / \mathrm{m} 2$. For health-related fitness outcomes at postintervention, the mean (and standard deviation) for $\mathrm{VO}_{2 \text { peak }}$ was $25.5(5.9) \mathrm{ml} / \mathrm{kg} / \mathrm{min}$, for $1 \mathrm{RM}$ was 26.5 (9.0) $\mathrm{kg}$ for chest press and 87.6 (28.5) $\mathrm{kg}$ for leg press, for lean body mass was $41.3(5.8) \mathrm{kg}$, and for body fat percent was 37.6 (8.5). For motivational variables at postintervention, the mean (and standard deviation) for TPB benefit was $4.9(0.4)$, enjoyment was 4.1 (0.9), support was $4.6(0.7)$, motivation was 4.4 (0.7), difficulty was 2.3 (1.0), and plan was 3.9 (1.1). The proportion of participants meeting neither, resistance only, aerobic only, and combined exercise guidelines at baseline, during the intervention (based on group assignment), and each of the three follow-up timepoints are presented in Fig. 1.

\section{Exercise patterns}

Patients with breast cancer exhibited 50 out of a possible 64 exercise patterns across the three timepoints when including the temporal sequence of the exercise behavior. Of the 14 exercise patterns that ignored the temporal sequence, the most common patterns were "alternating combined or aerobic only" (21.2\%), "alternating aerobic only or neither" (13.7\%), "always neither" (11\%), "always combined" (9.5\%), and "always aerobic only" (8.0\%), which accounted for $63.4 \%$ of all patterns (Table 1; Fig. 2). The percentage of participants who reported "combined exercise" $0,1,2$, and 3 times during follow-up were $46.1 \%, 27.3 \%, 17.4 \%$, and $9.5 \%$, respectively. Similarly, the percentage of participants who reported "neither" $0,1,2$, and 3 times during follow-up were $52.0 \%, 21.1 \%, 16.1 \%$, and $11.0 \%$, respectively. 
Predictors of exercise behavior at 6-month follow-up

The significant univariate predictors of exercise behavior at 6-month follow-up were group assignment $(p=0.016)$, study site $(p=0.046)$, aerobic fitness $(p<0.001)$, upper body strength $(p=0.005)$, lower body strength $(p=0.035)$, lower body endurance $(p=0.038)$, fat mass $(p=0.007)$, body fat percent $(p=0.005)$, the Physical Component Summary domain of the SF-36 $(p=0.006)$, fatigue $(p=0.019)$, taxane symptom $(p=0.016)$, TPB enjoyment $(p=0.009)$, TPB support $(p=0.034)$, TPB motivation $(p<0.001)$, TPB difficulty $(p=0.003)$, and TPB planning $(p<0.001)$. The significant multivariate predictors of exercise behavior at 6-month follow-up were aerobic fitness, motivation, and planning (Table 2). Specifically, higher aerobic fitness (per $1 \mathrm{ml} / \mathrm{kg} /$ min) was associated with better adherence to the "aerobic only" (OR = 1.09; $p=0.005)$ and "combined" $(\mathrm{OR}=1.12$; $\mathrm{p}<0.001)$ guidelines compared to "neither" guideline. Additionally, participants with higher aerobic fitness (per $1 \mathrm{ml} /$ $\mathrm{kg} / \mathrm{min}$ ) were more likely to meet the "aerobic only" (OR = $1.10 ; p=0.029)$ and "combined" (OR $=1.12 ; p=0.006)$ guidelines when compared to the "resistance only" guideline. Moreover, participants were more likely to be meeting the "combined" guidelines compared to "neither" if they had higher motivation $(\mathrm{OR}=2.03$ per 1 point; $p=0.006)$ and a more specific plan $(\mathrm{OR}=1.59$ per 1 point; $p=0.008)$ for exercise postintervention.

\section{Predictors of exercise behavior at 12-month follow-up}

The significant univariate predictors of exercise behavior at 12 -month follow-up were age $(p=0.014)$, aerobic fitness $(p<0.001)$, upper body strength $(p=0.013)$, lower body strength $(p=0.028)$, lower body endurance $(p=$ $0.020)$, body fat percent $(p=0.017)$ PCS $(p<0.001)$, sleep quality $(p=0.032)$, TPB motivation $(p=0.017)$ and TPB difficulty $(p=0.018)$. The significant multivariate predictors of exercise behavior at 12-month follow-up were
Table 1 Exercise patterns across the three follow-up timepoints in breast cancer patients who exercised during chemotherapy

\begin{tabular}{|c|c|c|c|}
\hline \multirow{2}{*}{\multicolumn{2}{|c|}{$\begin{array}{l}\text { Pattern } \\
\text { Same exercise guideline at each of the three } \\
\text { timepoints }\end{array}$}} & \multirow[t]{2}{*}{$\mathrm{N}$} & \multirow[t]{2}{*}{$\%$} \\
\hline & & & \\
\hline 1 & Neither & 29 & 11.0 \\
\hline 2 & Combined & 25 & 9.5 \\
\hline 3 & Aerobic only & 21 & 8.0 \\
\hline 4 & Resistance only & 4 & 1.5 \\
\hline \multicolumn{4}{|c|}{$\begin{array}{l}\text { Alternating two exercise guidelines across the } \\
\text { three timepoints (in any order) }\end{array}$} \\
\hline 5 & Combined / Aerobic only & 56 & 21.2 \\
\hline 6 & Aerobic only / Neither & 36 & 13.7 \\
\hline 7 & Combined / Resistance only & 19 & 7.2 \\
\hline 8 & Combined / Neither & 19 & 7.2 \\
\hline 9 & Resistance only / Neither & 17 & 6.5 \\
\hline 10 & Aerobic only / Resistance only & 8 & 3.1 \\
\hline \multicolumn{4}{|c|}{$\begin{array}{l}\text { Different exercise guideline at each of the } \\
\text { three timepoints (in any order) }\end{array}$} \\
\hline 11 & Combined / Aerobic only / Neither & 16 & 6.0 \\
\hline 12 & Aerobic only / Resistance only / Neither & 6 & 2.3 \\
\hline 13 & Combined / Resistance only / Neither & 4 & 1.5 \\
\hline 14 & Combined / Aerobic only / Resistance only & 4 & 1.5 \\
\hline Total & & 264 & 100 \\
\hline
\end{tabular}

aerobic fitness, sleep quality, difficulty, and lower body endurance (Table 3). Participants with higher aerobic fitness (per $1 \mathrm{ml} / \mathrm{kg} / \mathrm{min}$ ) were more likely to meet the "aerobic only" guideline $(\mathrm{OR}=1.12 ; p<0.001)$ when compared to "neither" guideline. Additionally, higher exercise difficulty (per 1 point) was associated with worse adherence to the "combined" guidelines compared to the "neither" guideline $(\mathrm{OR}=0.60 ; p=0.004)$, and participants with lower

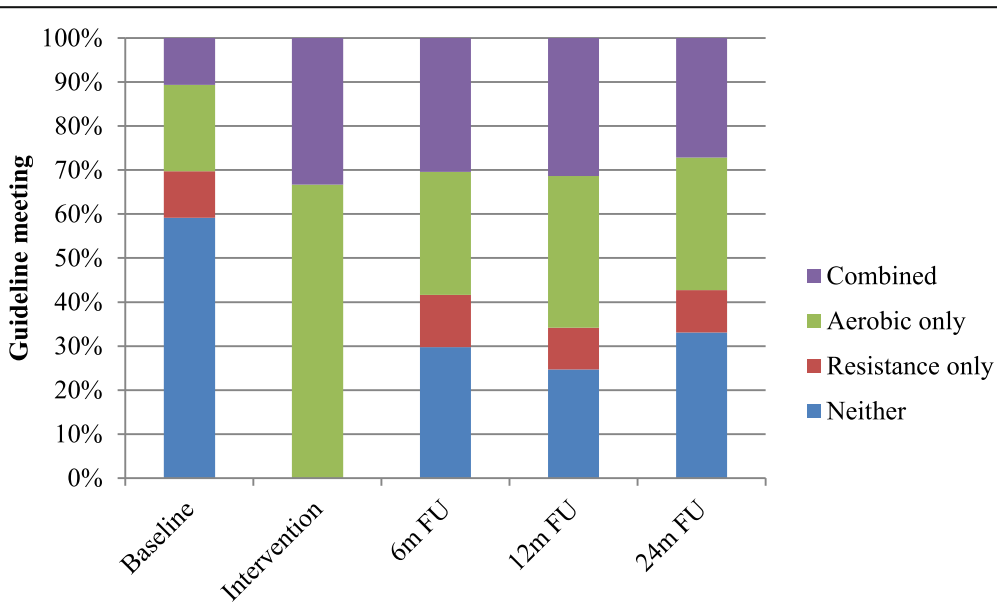

Time Point

Fig. 1 Proportion of participants meeting exercise guidelines. Note: intervention = randomized intervention period during chemotherapy 


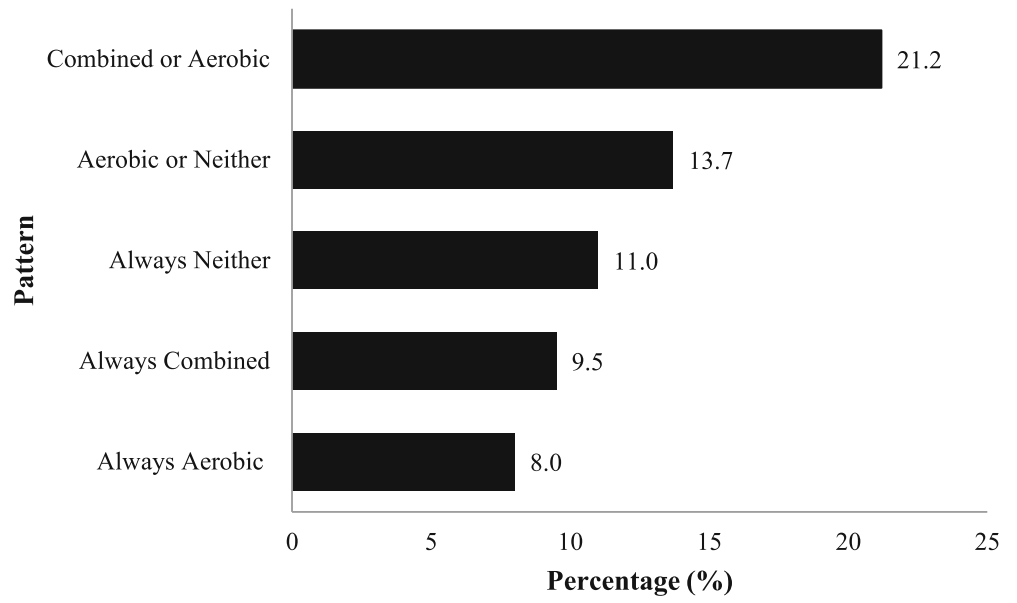

Fig. 2 Most common exercise patterns of breast cancer patients during follow-up after exercise training during chemotherapy. Note: Aerobic = meeting aerobic exercise guideline only; Neither = meeting neither exercise guideline; Combined = meeting both exercise guidelines

sleep quality (per 1 point) were more likely to meet the "combined" guidelines compared to the "aerobic only" $(\mathrm{OR}=1.11 ; p=0.005)$ and "resistance only" guideline $(\mathrm{OR}=1.13 ; p=0.049)$. Lastly, lower body endurance (per 1 repetition) predicted aerobic exercise $(\mathrm{OR}=1.02 ; p=$ $0.043)$ and combined exercise $(\mathrm{OR}=1.02 ; p=0.015)$ compared to resistance exercise.

\section{Predictors of exercise behavior at 24-month follow-up}

The significant univariate predictors of exercise behavior at 24-month follow-up were study site $(p=0.049)$, aerobic fitness $(p=0.001)$, upper body strength $(p<0.001)$, lower body strength $(p<0.001)$, lower body endurance $(p=0.024)$, body fat percent $(p=0.016)$, taxane symptoms $(p=0.031)$, selfesteem $(p=0.026)$, TPB enjoyment $(p=0.017)$, TPB motivation $(p=0.001)$, TPB difficulty $(p=0.002)$, and TPB planning $(p=0.006)$. The significant multivariate predictors of exercise behavior at 24-month follow-up were upper body strength, difficulty, and aerobic fitness (Table 4). Higher upper body strength (per $1 \mathrm{~kg}$ ) was associated with better adherence to the "combined" $(\mathrm{OR}=1.08 ; p<0.001)$ and "resistance only" $(\mathrm{OR}=1.07 ; p=0.025)$ guidelines compared to the "neither" guideline; and the "combined" guideline $(\mathrm{OR}=1.05 ; p=0.023)$ compared to the "aerobic only" guideline. Participants with lower exercise difficulty (per 1 point) were more likely to meet the "aerobic only" (OR = $0.58 ; p=0.002)$ and the "combined" guideline $(\mathrm{OR}=0.62$; $p=0.010$ ) compared to "neither" guideline. Moreover, higher aerobic fitness (per $1 \mathrm{ml} / \mathrm{kg} / \mathrm{min}$ ) was associated with better adherence to the "aerobic only" (OR $=1.09 ; p=0.004)$ and the "combined" guidelines $(\mathrm{OR}=1.07 ; p=0.031)$ compared to "neither" guideline.

\section{Predictors of exercise pattern during follow-up}

Table 5 presents the predictors of the frequency of meeting the "combined" guideline or "neither" guideline during follow-up. The significant univariate predictors of the frequency of meeting the "combined" guideline during followup were aerobic fitness $(p=0.035)$, upper body strength $(p=0.001)$, lower body strength $(p=0.002)$, lower body

Table 2 Stepwise multinomial logistic regression model estimating predictors of exercise behavior at 6-month follow-up $(n=263)$

\begin{tabular}{|c|c|c|c|c|c|c|}
\hline \multirow[t]{2}{*}{ Step/predictors } & \multicolumn{2}{|c|}{ Resistance vs. Neither } & \multicolumn{2}{|c|}{ Aerobic vs. Neither } & \multicolumn{2}{|c|}{ Combined vs. Neither } \\
\hline & OR $(95 \% \mathrm{Cl})$ & $p$ & OR $(95 \% \mathrm{Cl})$ & $p$ & OR $(95 \% \mathrm{Cl})$ & $p$ \\
\hline 1. $\mathrm{VO}_{\text {2peak }}(\mathrm{mL} / \mathrm{kg} \cdot \mathrm{min})$ & $0.99(0.91-1.08)$ & 0.90 & $1.09(1.03-1.16)$ & 0.005 & $1.12(1.05-1.19)$ & $<0.001$ \\
\hline 2. TPB Motivation (1-5) & $1.25(0.68-2.29)$ & 0.47 & $1.47(0.93-2.31)$ & 0.10 & $2.03(1.22-3.36)$ & 0.006 \\
\hline \multirow[t]{3}{*}{ 3. TPB Plan (1-5) } & $1.51(0.96-2.40)$ & 0.08 & $1.28(0.92-1.76)$ & 0.14 & $1.59(1.13-2.23)$ & 0.008 \\
\hline & \multicolumn{2}{|c|}{ Aerobic vs. Resistance } & \multicolumn{2}{|c|}{ Combined vs. Aerobic } & \multicolumn{2}{|c|}{ Combined vs. Resistance } \\
\hline & OR $(95 \% \mathrm{Cl})$ & $p$ & OR $(95 \% \mathrm{Cl})$ & $p$ & OR $(95 \% \mathrm{Cl})$ & $p$ \\
\hline 1. $\mathrm{VO}_{\text {2peak }}(\mathrm{mL} / \mathrm{kg} \cdot \mathrm{min})$ & $1.10(1.01-1.19)$ & 0.029 & $1.02(0.97-1.08)$ & 0.37 & $1.12(1.03-1.22)$ & 0.006 \\
\hline 2. TPB Motivation [1-5] & $1.17(0.62-2.21)$ & 0.62 & $1.38(0.83-2.30)$ & 0.22 & $1.62(0.84-3.15)$ & 0.15 \\
\hline 3. TPB Plan [1-5] & $0.84(0.53-1.34)$ & 0.47 & $1.25(0.90-1.72)$ & 0.18 & $1.05(0.65-1.69)$ & 0.84 \\
\hline
\end{tabular}

Resistance = meeting resistance exercise guideline only; Aerobic = meeting aerobic exercise guideline only; Neither = meeting neither exercise guideline; Combined = meeting both exercise guidelines; TPB = theory of planned behavior, OR represents the change in the odds of a meeting a guideline for a one-unit change in the variables 
Table 3 Stepwise multinomial logistic regression model estimating predictors of exercise behavior at 12- month follow-up $(n=263)$

\begin{tabular}{|c|c|c|c|c|c|c|}
\hline \multirow[t]{2}{*}{ Step/predictors } & \multicolumn{2}{|c|}{ Resistance vs. Neither } & \multicolumn{2}{|c|}{ Aerobic vs. Neither } & \multicolumn{2}{|c|}{ Combined vs. Neither } \\
\hline & OR $(95 \% \mathrm{Cl})$ & $p$ & OR $(95 \% \mathrm{Cl})$ & $p$ & OR $(95 \% \mathrm{Cl})$ & $p$ \\
\hline 1. $\mathrm{VO}_{2 \text { peak }}(\mathrm{mL} / \mathrm{kg} \cdot \mathrm{min})$ & $1.04(0.95-1.15)$ & 0.38 & $1.12(1.05-1.20)$ & $<0.001$ & $1.07(1.00-1.14)$ & 0.05 \\
\hline 2. TPB Difficulty $(1-5)^{\text {a }}$ & $0.91(0.56-1.48)$ & 0.72 & $0.80(0.58-1.12)$ & 0.19 & $0.60(0.43-0.85)$ & 0.004 \\
\hline 3. Sleep quality $(0-21)^{a}$ & $0.93(0.83-1.06)$ & 0.27 & $0.95(0.88-1.03)$ & 0.23 & $1.05(0.98-1.14)$ & 0.19 \\
\hline \multirow[t]{3}{*}{ 4. lower body endurance (reps) } & $0.99(0.97-1.00)$ & 0.12 & $1.00(1.00-1.01)$ & 0.42 & $1.01(1.00-1.02)$ & 0.11 \\
\hline & \multicolumn{2}{|c|}{ Aerobic vs. Resistance } & \multicolumn{2}{|c|}{ Combined vs. Aerobic } & \multicolumn{2}{|c|}{ Combined vs. Resistance } \\
\hline & OR $(95 \% \mathrm{Cl})$ & $p$ & OR $(95 \% \mathrm{Cl})$ & $p$ & OR $(95 \% \mathrm{Cl})$ & $p$ \\
\hline 1. $\mathrm{VO}_{2 \text { peak }}(\mathrm{mL} / \mathrm{kg} \cdot \mathrm{min})$ & $1.08(0.98-1.18)$ & 0.11 & $0.95(0.90-1.00)$ & 0.06 & $1.02(0.93-1.12)$ & 0.64 \\
\hline 2. TPB Difficulty $(1-5)^{\text {a }}$ & $0.88(0.55-1.41)$ & 0.59 & $0.75(0.55-1.03)$ & 0.07 & $0.66(0.40-1.07)$ & 0.09 \\
\hline 3. Sleep quality (0-21) ${ }^{a}$ & $1.02(0.91-1.15)$ & 0.73 & $1.11(1.03-1.19)$ & 0.005 & $1.13(1.00-1.27)$ & 0.049 \\
\hline 4. lower body endurance (reps) & $1.02(1.00-1.04)$ & 0.043 & $1.00(1.00-1.01)$ & 0.30 & $1.02(1.00-1.04)$ & 0.015 \\
\hline
\end{tabular}

Resistance = meeting resistance exercise guideline only; Aerobic = meeting aerobic exercise guideline only; Neither = meeting neither exercise guideline; Combined = meeting both exercise guidelines; TPB = theory of planned behavior, OR represents the change in the odds of a meeting a guideline for a one-unit change in the variables

${ }^{a}$ High scores indicate higher difficulty in exercise and worse sleep quality

endurance $(p=0.014)$, fatigue $(p=0.017)$, TPB motivation $(p<0.001)$, TPB difficulty $(p=0.020)$, and TPB plan $(p=$ $0.002)$. In terms of multivariate predictors, upper body strength ( $\beta=0.19 ; p=0.003$ ), motivation ( $\beta=0.17 ; p=0.006)$, and lower body endurance ( $\beta=0.14 ; p=0.030$ ) were associated with the frequency of meeting the "combined" guideline during follow-up.

The significant univariate predictors of the frequency of meeting "neither" guideline during follow-up were study site $(p=0.020)$, aerobic fitness $(p<0.001)$, upper body strength $(p=0.002)$, lower body strength $(p=0.003)$, fat mass $(p=$ $0.037)$, body fat percent $(p=0.017)$, the Physical Component Summary domain of the SF-36 $(p=0.009)$, TPB enjoyment $(p=0.007)$, TPB motivation $(p<0.001)$, TPB difficulty $(p<$ $0.001)$, and TPB planning $(p=0.005)$. In terms of multivariate predictors, aerobic fitness $(\beta=-0.20 ; p=0.001)$, exercise difficulty $(\beta=0.22 ; p<0.001)$, lower body strength $(\beta=-$
$0.21 ; p=0.001$ ), and study site (Edmonton versus Ottawa/ Vancouver) $(\beta=-0.16 ; p=0.009)$ were associated with the frequency of meeting "neither" guideline during follow-up.

\section{Discussion}

The purpose of the current study was to report the patterns and predictors of exercise behavior during 24 months of follow-up in patients with breast cancer who exercised during chemotherapy. The exercise patterns in our findings showed that patients with breast cancer exercised more during follow-up than at baseline but still showed a decline from the intervention period. The decline appeared immediately at 6-month follow-up and then remained stable at 12- and 24-month follow-up. Previous studies examining exercise interventions during breast cancer treatment have shown similar results. Husebo et al. [44] reported that physical activity levels at posttreatment and at 6-month follow-

Table 4 Stepwise multinomial logistic regression model estimating predictors of exercise behavior at 24-month follow-up ( $n=248$ )

\begin{tabular}{|c|c|c|c|c|c|c|}
\hline \multirow[t]{2}{*}{ Step/predictors } & \multicolumn{2}{|c|}{ Resistance vs. Neither } & \multicolumn{2}{|c|}{ Aerobic vs. Neither } & \multicolumn{2}{|c|}{ Combined vs. Neither } \\
\hline & OR $(95 \% \mathrm{Cl})$ & $p$ & OR $(95 \% \mathrm{Cl})$ & $p$ & OR $(95 \% \mathrm{Cl})$ & $p$ \\
\hline 1. Upper body strength (kg) & $1.07(1.01-1.13)$ & 0.025 & $1.04(0.99-1.08)$ & 0.10 & $1.08(1.04-1.13)$ & $<0.001$ \\
\hline 2. TPB Difficulty $(1-5)^{a}$ & $0.86(0.53-1.40)$ & 0.54 & $0.58(0.41-0.82)$ & 0.002 & $0.62(0.43-0.89)$ & 0.010 \\
\hline \multirow[t]{3}{*}{ 3. $\mathrm{VO}_{2 \text { peak }}(\mathrm{mL} / \mathrm{kg} \cdot \mathrm{min})$} & $1.01(0.93-1.11)$ & 0.77 & $1.09(1.03-1.16)$ & 0.004 & $1.07(1.01-1.14)$ & 0.031 \\
\hline & \multicolumn{2}{|c|}{ Aerobic vs. Resistance } & \multicolumn{2}{|c|}{ Combined vs. Aerobic } & \multicolumn{2}{|c|}{ Combined vs. Resistance } \\
\hline & OR $(95 \% \mathrm{Cl})$ & $p$ & OR $(95 \% \mathrm{Cl})$ & $p$ & OR $(95 \% \mathrm{Cl})$ & $p$ \\
\hline 1. Upper body strength (kg) & $0.97(0.92-1.03)$ & 0.28 & $1.05(1.01-1.09)$ & 0.023 & $1.02(0.96-1.07)$ & 0.58 \\
\hline 2. TPB Difficulty $[1-5]^{\text {a }}$ & $0.67(0.41-1.10)$ & 0.11 & $1.08(0.76-1.54)$ & 0.67 & $0.72(0.44-1.19)$ & 0.20 \\
\hline 3. $\mathrm{VO}_{2 \text { peak }}(\mathrm{mL} / \mathrm{kg} \cdot \mathrm{min})$ & $1.08(0.99-1.17)$ & 0.10 & $0.98(0.93-1.04)$ & 0.52 & $1.06(0.97-1.15)$ & 0.22 \\
\hline
\end{tabular}

Resistance = meeting resistance exercise guideline only; Aerobic = meeting aerobic exercise guideline only; Neither = meeting neither exercise guideline; Combined $=$ meeting both exercise guidelines; TPB = theory of planned behavior, OR represents the change in the odds of a meeting a guideline for a one-unit change in the variables

${ }^{a}$ High scores indicate higher difficulty in exercise 
Table 5 Stepwise linear regression model estimating predictors of the frequency of meeting the "Combined" or "Neither" guideline during follow-up $(n=245)$

\begin{tabular}{|c|c|c|c|}
\hline \multirow[b]{2}{*}{ Step/predictors } & \multicolumn{2}{|c|}{ Number of Combined (0-3) } & \multirow[b]{2}{*}{$p$} \\
\hline & Unstandardized B (95\% Cl) & Standardized $\beta$ & \\
\hline 1. Upper body strength & 0.02 (0.01 to 0.04$)$ & 0.19 & 0.003 \\
\hline 2. TPB Motivation & 0.23 (0.07 to 0.40$)$ & 0.17 & 0.006 \\
\hline \multirow[t]{3}{*}{ 3. Lower body endurance } & $0.00(0.00$ to 0.06$)$ & 0.14 & 0.030 \\
\hline & \multicolumn{2}{|c|}{ Number of Neither $(0-3)$} & \\
\hline & Unstandardized B $(95 \% \mathrm{Cl})$ & Standardized $\beta$ & $p$ \\
\hline 1. $\mathrm{VO}_{2 \text { peak }}$ & $-0.03(-0.05$ to -0.01$)$ & -0.20 & 0.001 \\
\hline 2. TPB Difficulty ${ }^{a}$ & 0.22 (0.11 to 0.34$)$ & 0.22 & $<0.001$ \\
\hline 3. Lower body strength & $-0.01(-0.01$ to -0.00$)$ & -0.21 & 0.001 \\
\hline 4. Site (Edmonton vs. Ottawa/Vancouver) & $-0.33(-0.58$ to -0.08$)$ & -0.16 & 0.009 \\
\hline
\end{tabular}

TPB $=$ theory of planned behavior

${ }^{a}$ High score indicates higher difficulty in exercise

up were higher than baseline even after a home-based intervention. Mutrie et al. [8] also reported that patients with breast cancer increased their leisure-time physical activity after a supervised intervention during treatment but it was not maintained at 6-month follow-up, although it was still higher than baseline. Additionally, Schmidt et al.'s study [14] showed that resistance training during treatment enhanced participation in resistance exercise after treatment, but the effect attenuated in the longer-term follow-up. These results suggest that exercise training during chemotherapy may help patients with breast cancer improve longer-term exercise behavior compared to baseline; however, additional interventions may be needed to sustain the exercise program that was initiated during chemotherapy.

A novel finding of our study is that the longer-term exercise patterns of patients with breast cancer who exercised during chemotherapy are diverse and unstable with 50 out of a possible 64 exercise patterns being exhibited. Moreover, only $30 \%$ of participants reported a stable exercise pattern (including no exercise) across all three timepoints. Ignoring the temporal sequence of the exercise patterns, the most common exercise patterns were: "alternating combined or aerobic only", "alternating aerobic only or neither", "always neither", "always combined", and "always aerobic" with over $60 \%$ of participants falling into these 5 patterns. The two most common exercise patterns appear to identify groups of patients with breast cancer who (a) are trying to add resistance exercise to aerobic exercise and (b) are trying to maintain aerobic exercise versus no exercise.

Few studies to date have reported exercise behavior patterns in cancer survivors because they have not assessed exercise behavior at multiple timepoints and/or they have not assessed aerobic and resistance exercise separately. Courneya and Friedenreich examined exercise patterns by asking colorectal [45] and breast [46] cancer survivors to retrospectively report their exercise behavior prediagnosis, during active treatment, and posttreatment. Both studies reported four main exercise patterns including maintainers (activeactive-active), temporary relapsers (active-inactive-active), permanent relapsers (active-inactive-inactive), and nonexercisers (inactive-inactive-inactive). Limitations of these studies included the retrospective design and the failure to assess aerobic and resistance exercise separately. Our study is the first study to report exercise patterns prospectively with multiple follow-up timepoints after chemotherapy and obtain separate assessments for the major exercise modalities. Our data indicate that exercise behavior patterns after exercising during breast cancer chemotherapy are highly variable and unstable. Consequently, identifying the key predictors of longer-term exercise behavior patterns is important to inform possible interventions to promote exercise after chemotherapy.

Interestingly, physical fitness was the most consistent predictor of exercise behavior in patients with breast cancer after chemotherapy. Although physical fitness is a predictor of exercise behavior in several populations [47, 48], few studies have examined it as a predictor of exercise behavior after breast cancer chemotherapy. Courneya et al. [17] reported strength improvements and postintervention body mass index predicted 6-month follow-up exercise behavior in patients with breast cancer after chemotherapy. Meanwhile, Schmidt et al. [14] reported that prediagnosis exercise levels predicted exercise behaviors at the 12-month followup but muscle strength and $\mathrm{VO}_{2 \text { peak }}$ did not. In our findings, aerobic fitness was the most important predictor of exercise behaviors, especially aerobic exercise. Aerobic fitness $\left(\mathrm{VO}_{2 \text { peak }}\right)$ predicted the inclusion of aerobic exercise in almost all exercise comparisons (e.g., aerobic versus neither, combined versus neither, combined versus resistance, number of neither) at almost all timepoints. Muscular fitness (endurance and strength) also predicted exercise behaviors, especially resistance exercise. Muscular fitness predicted the 
inclusion of resistance exercise behavior in multiple comparisons (e.g., resistance versus neither, combined versus neither, number of combined) at various timepoints. It seems clear that physical fitness after chemotherapy is a key predictor of longer-term exercise behavior in patients with breast cancer. These findings suggest that exercise programs that improve, or at least maintain, physical fitness during breast cancer chemotherapy may also improve longer-term exercise adherence. Moreover, clinical exercise specialists may want to target patients with breast cancer with low physical fitness after chemotherapy for a more intensive exercise behavior change program.

In addition to physical fitness, TPB motivational variables (difficulty, motivation, and planning) also predicted exercise behaviors, especially in comparison to neither (e.g., aerobic versus neither, combined versus neither, number of neither). Motivational variables are strong predictors of exercise behavior in many cancer survivor populations [49, 50], however, few studies have examined motivational variables as predictors of exercise behavior after exercising during chemotherapy. Courneya et al. [17] reported that instrumental attitude (perceived benefits) predicted exercise behavior 6 months after chemotherapy and Emery et al. [16] reported that family support predicted exercise behavior in breast cancer survivors 5-years after treatment. Our findings showed that intention (motivation and planning) is associated with short-term exercise behavior whereas perceived behavioral control (difficulty) is associated with longer-term exercise behavior after chemotherapy in patients with breast cancer. These findings suggest that clinical exercise specialists should help patients with breast cancer stay motivated by emphasizing novel and important benefits, developing a specific plan, and reducing the perceived difficulty of continuing to exercise after breast cancer chemotherapy.

It is also instructive to know the many variables that were not key predictors of longer-term exercise behavior. Of all the patient-reported outcomes examined, only sleep quality predicted exercise behavior but it was inconsistent. Demographic variables were not related to longer-term exercise behavior in multivariate analyses. Moreover, medical variables did not predict exercise behaviors after chemotherapy even in univariate analyses in the current study. However, several previous studies reported medical variables including surgery type, disease stage, and the receipt of chemotherapy associated with exercise behavior after breast cancer chemotherapy $[16,17]$. Whether or not medical variables are associated with long-term exercise behaviors in patients with breast cancer after chemotherapy is still unclear and should be explored further. Finally, age, group assignment, fat mass, percent body fat, physical component score, taxane and endocrine symptoms, self-esteem, anxiety, TPB enjoyment, and TPB support were associated with exercise behavior in univariate but not multivariate analyses. These variables may be associated with exercise behavior and should be considered candidate predictors in future studies.

Our study has important strengths and weaknesses. Strengths of the present study include the multiple longer-term (6-, 12-, and 24-month) follow-ups, the separate assessment of aerobic and resistance exercise, the large sample size, the comprehensive assessment of candidate predictors, the objective measures of physical fitness, and the excellent follow-up rate. Moreover, the current study design is clinically relevant because it attempts to predict follow-up exercise behavior in patients with breast cancer who received supervised exercised during chemotherapy, which is quickly becoming the standard of care. Additionally, the findings of this study have practical implications. All significant predictors in multivariate analyses were modifiable factors, which means that it is clearly possible to change these factors to improve longer-term exercise behavior. Limitations of the present study include the selfreported exercise behavior, the homogeneous sample which may limit the generalizability of the results, the collapse of exercise patterns ignoring temporal sequence due to too many patterns, and different sample sizes at each timepoint. Another limitation is that we did not assess the measurement properties of our single item assessments of the motivational variables in our study and recommend multi-item assessments for future studies.

In summary, we examined the patterns and predictors of longer-term exercise behavior in patients with breast cancer who exercised during chemotherapy. We found that patients with breast cancer exhibited varied and inconsistent exercise patterns across the three longer-term follow-ups. The most common exercise patterns included a group of patients with breast cancer who oscillated between combined exercise and aerobic exercise only, and another group that oscillated between aerobic exercise only and no exercise. Moreover, the most consistent predictors of longer-term exercise behavior were physical fitness and motivational variables, whereas patient-reported outcomes, demographic, and medical variables played a limited role. These predictors should be targeted to help patients with breast cancer maintain exercise after chemotherapy and into survivorship. More specifically, medical professionals and exercise specialists should assist patients with breast cancer to maintain their physical fitness during treatment and counsel them on overcoming barriers and developing a detailed plan to continue exercise after chemotherapy.

Acknowledgements

Not applicable.

Ethics registration number BR-01-0080 ethics 22148. 


\section{Authors' contribution}

KY An had full access to all of the data in the study and takes responsibility for the integrity of the data and the accuracy of the data analysis. KS Courneya, DC McKenzie, JR Mackey, K Gelmon, CM Fridenreich, and RD Reid were responsible for the study concept and design. KY An, AR Morielli, DW Kang, and KS Courneya were responsible for the analysis and interpretation of data. KY An was responsible for the drafting of the manuscript. AR Morielli, DW Kang, DC McKenzie, JR Mackey, K Gelmon, CM Fridenreich, RD Reid and KS Courneya were responsible for critical revision of the manuscript for important intellectual content and provided administrative, technical, or material support. KY An and KS Courneya were responsible for statistical analysis. DC McKenzie, JR Mackey, K Gelmon, CM Fridenreich, RD Reid, and KS Courneya obtained funding. The study sponsors had no role in the design of the study; the collection, analysis, and interpretation of the data; the writing of the manuscript; and the decision to submit the manuscript for publication.

\section{Funding}

This work was supported by the Canadian Breast Cancer Research Alliance (No. 09843). K.S. Courneya is supported by the Canada Research Chairs Program. A.R. Morielli is supported by a Frederick Banting and Charles Best Canada Graduate Scholarship from the Canadian Institutes of Health Research. D.W. Kang is supported by an Alberta Innovates Graduate Studentship. C.M. Friedenreich was supported by a Health Senior Scholar award from Alberta Innovates Health Solution and the Alberta Cancer Foundation Weekend to End Women's Cancers Breast Cancer Chair.

\section{Availability of data and materials}

The data that support the findings of this study are available from the corresponding author upon reasonable request.

\section{Ethics approval and consent to participate}

Ethics approval was received from all three centers (the Cross Cancer Institute in Edmonton, Alberta; the Ottawa Hospital Cancer Center in Ottawa, Ontario; and the British Columbia Cancer Agency in Vancouver, British Columbia) and written informed consent was obtained from all participants. This study was performed in accordance with the Declaration of Helsinki.

\section{Consent for publication}

Not applicable.

\section{Competing interests}

The authors declare that they have no competing interests.

\section{Author details}

${ }^{1}$ Faculty of Kinesiology, Sport, and Recreation, University of Alberta, Edmonton, Alberta T6G 2H9, Canada. ${ }^{2}$ Alberta Health Services, Calgary, Alberta, Canada. ${ }^{3}$ University of Calgary, Calgary, Alberta, Canada. ${ }^{4}$ University of Ottawa Heart Institute, Ottawa, Ontario, Canada. ${ }^{5}$ University of British Columbia, Vancouver, British Columbia, Canada. ${ }^{6}$ British Columbia Cancer Agency, Vancouver, British Columbia, Canada. 'Cross Cancer Institute, Edmonton, Albera, Canada.

\section{Received: 30 August 2019 Accepted: 6 February 2020}

\section{Published online: 14 February 2020}

\section{References}

1. Caspersen CJ, Powell KE, Christenson GM. Physical activity, exercise, and physical fitness: definitions and distinctions for health-related research. Public Health Rep. 1985;100(2):126-31.

2. Courneya KS, McKenzie DC, Mackey JR, Gelmon K, Friedenreich CM, Yasui Y, et al. Effects of exercise dose and type during breast cancer chemotherapy: multicenter randomized trial. J Natl Cancer Inst. 2013;105(23):1821-32.

3. Courneya KS, Segal RJ, Mackey JR, Gelmon K, Reid RD, Friedenreich CM, et al. Effects of aerobic and resistance exercise in breast cancer patients receiving adjuvant chemotherapy: a multicenter randomized controlled trial. J Clin Oncol. 2007;25(28):4396-404.

4. Schmitz KH, Courneya KS, Matthews C, Demark-Wahnefried W, Galvao DA, Pinto BM, et al. American College of Sports Medicine roundtable on exercise guidelines for cancer survivors. Med Sci Sports Exerc. 2010;42(7): $1409-26$.
5. van Waart H, Stuiver MM, van Harten WH, Geleijn E, Kieffer JM, Buffart LM, et al. Effect of low-intensity physical activity and moderate- to Highintensity physical exercise during adjuvant chemotherapy on physical fitness, fatigue, and chemotherapy completion rates: results of the PACES randomized clinical trial. J Clin Oncol. 2015;33(17):1918-27.

6. Courneya KS, Segal RJ, Mackey JR, Gelmon K, Friedenreich CM, Yasui Y, et al. Effects of exercise dose and type on sleep quality in breast cancer patients receiving chemotherapy: a multicenter randomized trial. Breast Cancer Res Treat. 2014;144(2):361-9.

7. Courneya KS, Segal RJ, McKenzie DC, Dong H, Gelmon K, Friedenreich CM, et al. Effects of exercise during adjuvant chemotherapy on breast cancer outcomes. Med Sci Sports Exerc. 2014;46(9):1744-51.

8. Mutrie N, Campbell AM, Whyte F, McConnachie A, Emslie C, Lee L, et al. Benefits of supervised group exercise programme for women being treated for early stage breast cancer: pragmatic randomised controlled trial. BMJ. 2007:334(7592):517.

9. Daley AJ, Crank H, Saxton JM, Mutrie N, Coleman R, Roalfe A. Randomized trial of exercise therapy in women treated for breast cancer. J Clin Oncol. 2007;25(13):1713-21

10. Courneya KS, Segal RJ, Gelmon K, Reid RD, Mackey JR, Friedenreich CM, et al. Six-month follow-up of patient-rated outcomes in a randomized controlled trial of exercise training during breast cancer chemotherapy. Cancer Epidemiol Biomark Prev. 2007;16(12):2572-8.

11. Mutrie N, Campbell A, Barry S, Hefferon K, McConnachie A, Ritchie D, et al. Five-year follow-up of participants in a randomised controlled trial showing benefits from exercise for breast cancer survivors during adjuvant treatment. Are there lasting effects? J Cancer Surviv. 2012;6(4):420-30.

12. Haines TP, Sinnamon P, Wetzig NG, Lehman M, Walpole E, Pratt T, et al. Multimodal exercise improves quality of life of women being treated for breast cancer, but at what cost? Randomized trial with economic evaluation. Breast Cancer Res Treat. 2010;124(1):163-75.

13. Witlox L, Hiensch AE, Velthuis MJ, Steins Bisschop CN, Los M, Erdkamp FLG, et al. Four-year effects of exercise on fatigue and physical activity in patients with cancer. BMC Med. 2018;16(1):86.

14. Schmidt ME, Wiskemann J, Ulrich CM, Schneeweiss A, Steindorf K. Selfreported physical activity behavior of breast cancer survivors during and after adjuvant therapy: 12 months follow-up of two randomized exercise intervention trials. Acta Oncol. 2017;56(4):618-27.

15. An KY, Morielli AR, Kang DW, Friedenreich CM, McKenzie DC, Gelmon K, et al. Effects of exercise dose and type during breast cancer chemotherapy on longer-term patient-reported outcomes and health-related fitness: a randomized controlled trial. Int J Cancer. 2020;146(1):150-60.

16. Emery CF, Yang HC, Frierson GM, Peterson L, Suh S. Determinants of physical activity among women treated for breast cancer in a 5-year longitudinal follow-up investigation. Psychooncology. 2009;18(4):377-86.

17. Courneya KS, Friedenreich CM, Reid RD, Gelmon K, Mackey JR, Ladha AB, et al. Predictors of follow-up exercise behavior 6 months after a randomized trial of exercise training during breast cancer chemotherapy. Breast Cancer Res Treat. 2009;114(1):179-87.

18. Ajzen I. The theory of planned behavior. Organ Behav Hum Decis Process. 1991;50(2):179-211.

19. Irwin ML, McTiernan A, Bernstein L, Gilliland FD, Baumgartner R, Baumgartner $\mathrm{K}$, et al. Physical activity levels among breast cancer survivors. Med Sci Sports Exerc. 2004;36(9):1484-91.

20. Pinto BM, Trunzo JJ, Reiss P, Shiu SY. Exercise participation after diagnosis of breast cancer: trends and effects on mood and quality of life. Psychooncology. 2002;11(5):389-400.

21. Vallance J, Plotnikoff RC, Karvinen KH, Mackey JR, Courneya KS. Understanding physical activity maintenance in breast cancer survivors. Am J Health Behav. 2010;34(2):225-36.

22. Services USDoHaH. 2008 Physical Activity Guidelines for Americans 2008 [Available from: http://www.health.gov/PAGuidelines.

23. Rock CL, Doyle C, Demark-Wahnefried W, Meyerhardt J, Courneya KS, Schwartz AL, et al. Nutrition and physical activity guidelines for cancer survivors. CA Cancer J Clin. 2012;62(4):243-74.

24. Godin G, Shephard RJ. A simple method to assess exercise behavior in the community. Can J Appl Sport Sci. 1985;10(3):141-6.

25. Ware JE Jr, Kosinski M, Bayliss MS, McHorney CA, Rogers WH, Raczek A. Comparison of methods for the scoring and statistical analysis of SF-36 health profile and summary measures: summary of results from the medical outcomes study. Med Care. 1995;33(4 Suppl):AS264-79. 
26. Brady MJ, Cella DF, Mo F, Bonomi AE, Tulsky DS, Lloyd SR, et al. Reliability and validity of the functional assessment of Cancer therapy-breast qualityof-life instrument. J Clin Oncol. 1997;15(3):974-86.

27. Yellen SB, Cella DF, Webster K, Blendowski C, Kaplan E. Measuring fatigue and other anemia-related symptoms with the functional assessment of Cancer therapy (FACT) measurement system. J Pain Symptom Manag. 1997; 13(2):63-74.

28. Fallowfield $\sqcup$, Leaity SK, Howell A, Benson S, Cella D. Assessment of quality of life in women undergoing hormonal therapy for breast cancer: validation of an endocrine symptom subscale for the FACT-B. Breast Cancer Res Treat. 1999;55(2):189-99.

29. Cella D, Peterman A, Hudgens S, Webster K, Socinski MA. Measuring the side effects of taxane therapy in oncology: the functional assesment of cancer therapy-taxane (FACT-taxane). Cancer. 2003;98(4):822-31.

30. Cohen S, Kamarck T, Mermelstein R. A global measure of perceived stress. J Health Soc Behav. 1983;24(4):385-96.

31. Fordyce MW. A review of research on the happiness measures: a sixty second index of happiness and mental health. Soc Indic Res. 1988;20(4): 355-81.

32. Rosenberg M. Society and the adolescent self-image. Princeton, NJ: Princeton University Press; 1965.

33. Kohout FJ, Berkman LF, Evans DA, Cornoni-Huntley J. Two shorter forms of the CES-D (Center for Epidemiological Studies Depression) depression symptoms index. J Aging Health. 1993;5(2):179-93.

34. Radloff LS. The CES-D scale: a self-report depression scale for research in the general population. Appl Psychol Meas. 1977;1(3):385-401.

35. Deshields T, Tibbs T, Fan MY, Taylor M. Differences in patterns of depression after treatment for breast cancer. Psychooncology. 2006;15(5):398-406.

36. Spielberger CD. Manual for the state-trait anxiety inventory. Consulting Psychologists Press; 1983

37. Beck SL, Schwartz AL, Towsley G, Dudley W, Barsevick A. Psychometric evaluation of the Pittsburgh sleep quality index in cancer patients. J Pain Symptom Manag. 2004;27(2):140-8.

38. Buysse DJ, Reynolds CF 3rd, Monk TH, Berman SR, Kupfer DJ. The Pittsburgh sleep quality index: a new instrument for psychiatric practice and research. Psychiatry Res. 1989;28(2):193-213.

39. Keats MR, Culos-Reed SN, Courneya KS, McBride M. Understanding physical activity in adolescent cancer survivors: an application of the theory of planned behavior. Psychooncology. 2007;16(5):448-57.

40. Jones LW, Courneya KS, Vallance JK, Ladha AB, Mant MJ, Belch AR, et al. Understanding the determinants of exercise intentions in multiple myeloma cancer survivors: an application of the theory of planned behavior. Cancer Nurs. 2006;29(3):167-75.

41. Blanchard CM, Courneya KS, Rodgers WM, Murnaghan DM. Determinants of exercise intention and behavior in survivors of breast and prostate cancer: an application of the theory of planned behavior. Cancer Nurs. 2002;25(2): 88-95.

42. Karvinen KH, Courneya KS, Plotnikoff RC, Spence JC, Venner PM, North S. A prospective study of the determinants of exercise in bladder cancer survivors using the theory of planned behavior. Support Care Cancer. 2009; 17(2):171-9.

43. Chen HN, Cohen P, Chen S. How big is a big odds ratio? Interpreting the magnitudes of odds ratios in epidemiological studies. Commun Stat-Simul C. 2010;39(4):860-4.

44. Husebo AM, Dyrstad SM, Mjaaland I, Soreide JA, Bru E. Effects of scheduled exercise on cancer-related fatigue in women with early breast cancer. ScientificWorldJournal. 2014;2014:271828.

45. Courneya KS, Friedenreich CM. Relationship between exercise pattern across the cancer experience and current quality of life in colorectal cancer survivors. J Altern Complement Med. 1997;3(3):215-26.

46. Courneya KS, Friedenreich CM. Relationship between exercise during treatment and current quality of life among survivors of breast cancer. J Psychosoc Oncol. 1998;15(3-4):35-57.

47. van Stralen MM, De Vries H, Mudde AN, Bolman C, Lechner LJHPR. Determinants of initiation and maintenance of physical activity among older adults: a literature review. Health Psychol Rev. 2009;3(2):147-207.

48. Courneya KS, Stevinson C, McNeely ML, Sellar CM, Friedenreich CM, PeddleMclntyre CJ, et al. Predictors of follow-up exercise behavior 6 months after a randomized trial of supervised exercise training in lymphoma patients. Psychooncology. 2012;21(10):1124-31.
49. Husebo AM, Dyrstad SM, Soreide JA, Bru E. Predicting exercise adherence in cancer patients and survivors: a systematic review and meta-analysis of motivational and behavioural factors. J Clin Nurs. 2013;22(1-2):4-21.

50. Thorsen L, Courneya KS, Stevinson C, Fossa SD. A systematic review of physical activity in prostate cancer survivors: outcomes, prevalence, and determinants. Support Care Cancer. 2008;16(9):987-97.

\section{Publisher's Note}

Springer Nature remains neutral with regard to jurisdictional claims in published maps and institutional affiliations.
Ready to submit your research? Choose BMC and benefit from:

- fast, convenient online submission

- thorough peer review by experienced researchers in your field

- rapid publication on acceptance

- support for research data, including large and complex data types

- gold Open Access which fosters wider collaboration and increased citations

- maximum visibility for your research: over $100 \mathrm{M}$ website views per year

At BMC, research is always in progress.

Learn more biomedcentral.com/submissions 